\title{
Unusual Cutaneous Metastases From Colon Adenocarcinoma
}

\author{
Penélope Correia ${ }^{1}$, Joana F. Correia ${ }^{1}$, Horácio Scigliano ${ }^{2}$, Mário Nora ${ }^{1}$ \\ 1. General Surgery, Centro Hospitalar de Entre Douro e Vouga, Santa Maria da Feira, PRT 2. Pathology, Centro \\ Hospitalar de Entre Douro e Vouga, Santa Maria da Feira, PRT
}

Corresponding author: Penélope Correia, penelopeccorreia@gmail.com

\begin{abstract}
Skin metastases from internal malignancies are rare, even more from colorectal tumours, and are usually a sign of disseminated disease with a poor prognosis. However, with increased numbers of cancer survivors, a high index of suspicion should exist during the evaluation of cutaneous lesions since it can be the initial sign of disease progression or even the first sign that triggers a malignancy diagnosis, potentially improving the patient's odds. Herein, we report a case of synchronous cutaneous metastases from colon adenocarcinoma with unusual localization on the back and forearm of a 65 -year-old man.
\end{abstract}

Categories: Dermatology, General Surgery, Oncology

Keywords: cutaneous metastasis, skin metastasis, colorectal adenocarcinoma

\section{Introduction}

The skin is a relatively unusual site for internal tumour metastasis and remains a neglected, although relevant contributor, especially when total cancer incidence increases and more cancer survivors require surveillance for relapse [1]. Its prevalence stands around 1-4.3\%, and major contributors from internal malignancies are breast and lung cancer, accounting for $32.7 \%$ and $13.2 \%$ of cases, respectively [1-6].

Review began 02/15/2021 Review ended 03/15/2021 Published 03/23/2021

\section{(c) Copyright 2021}

Correia et al. This is an open access article distributed under the terms of the Creative Commons Attribution License CC-BY 4.0., which permits unrestricted use, distribution, and reproduction in any medium, provided the original author and source are credited.
Although cutaneous metastases are usually a late manifestation of widely disseminated known malignant disease, in around $16-21 \%$ of cases they are the first sign of internal malignancy, as they are discovered before the underlying primary tumour $[1,4,7]$.

Colorectal cancer (CRC) is one of the most frequently occurring cancers around the world, with $10 \%$ of them being diagnosed in stage IV [8]. The more common sites of metastasis are the liver, lung and central nervous system. Cutaneous metastases from colorectal cancer are extremely rare (4.2\%) and indicative of poor prognosis, reflecting the spread of disease [1-3,6,9]. The most frequent sites of cutaneous metastasis are incisional scars at the abdominal wall, scalp, face and neck [4-5].

We present a case of synchronous cutaneous metastases from colon adenocarcinoma in an unusual localization.

\section{Case Presentation}

A 65-year-old Caucasian autonomous male without relevant past medical history presented to the emergency service in September 2019 with a one-month evolution history of worsening of his constitutional status, with a weight loss of $7 \mathrm{~kg}$, associated with abdominal pain and distention with the sensation of reduced faecal transit. At clinical observation, he was thin, subicteric with a distended abdomen, which was slightly painful, without signs of peritoneal irritation. Analysis showed discreet leucocytosis and a cholestasis pattern with a total bilirubin of $2.94 \mathrm{mg} / \mathrm{dL}$, lactate dehydrogenase of $510 \mathrm{U} / \mathrm{L}$ and C-reactive protein of $88 \mathrm{mg} / \mathrm{L}$. Abdominal-pelvic CT-scan revealed multiple hepatic lesions suspicious of metastases, ascites and an irregular segmental wall thickening in the proximal sigmoid with permeable lumen and without imaging signs of occlusion.

He was admitted for study and, from the performed exams, the presence of the following was noted: several nodules in the lungs and liver compatible with secondary lesions, moderate volume ascites, heterogeneous densification of peritoneal fat suggesting peritoneal carcinomatosis; irregular parietal thickening of proximal sigmoid colon, in relation to neoformative lesion; and multiple adenopathies (Figure 1). Carcinoembryonic antigen was recorded at $>15000 \mu \mathrm{g} / \mathrm{L}$. Rectosigmoidoscopy identified and biopsied the lesion at $35 \mathrm{~cm}$ of anal margin. We also identified two nodular, painless, hard and mobile cutaneous lesions, without ulceration: one at the back measuring approximately $4 \mathrm{~cm}$ and another at the forearm measuring 1.5 $\mathrm{cm}$, and with a one-week evolution, that was excised for analysis (Figure 2). After clinical stabilization and pain control, the patient was discharged on the eighth day. 


\section{Cureus}

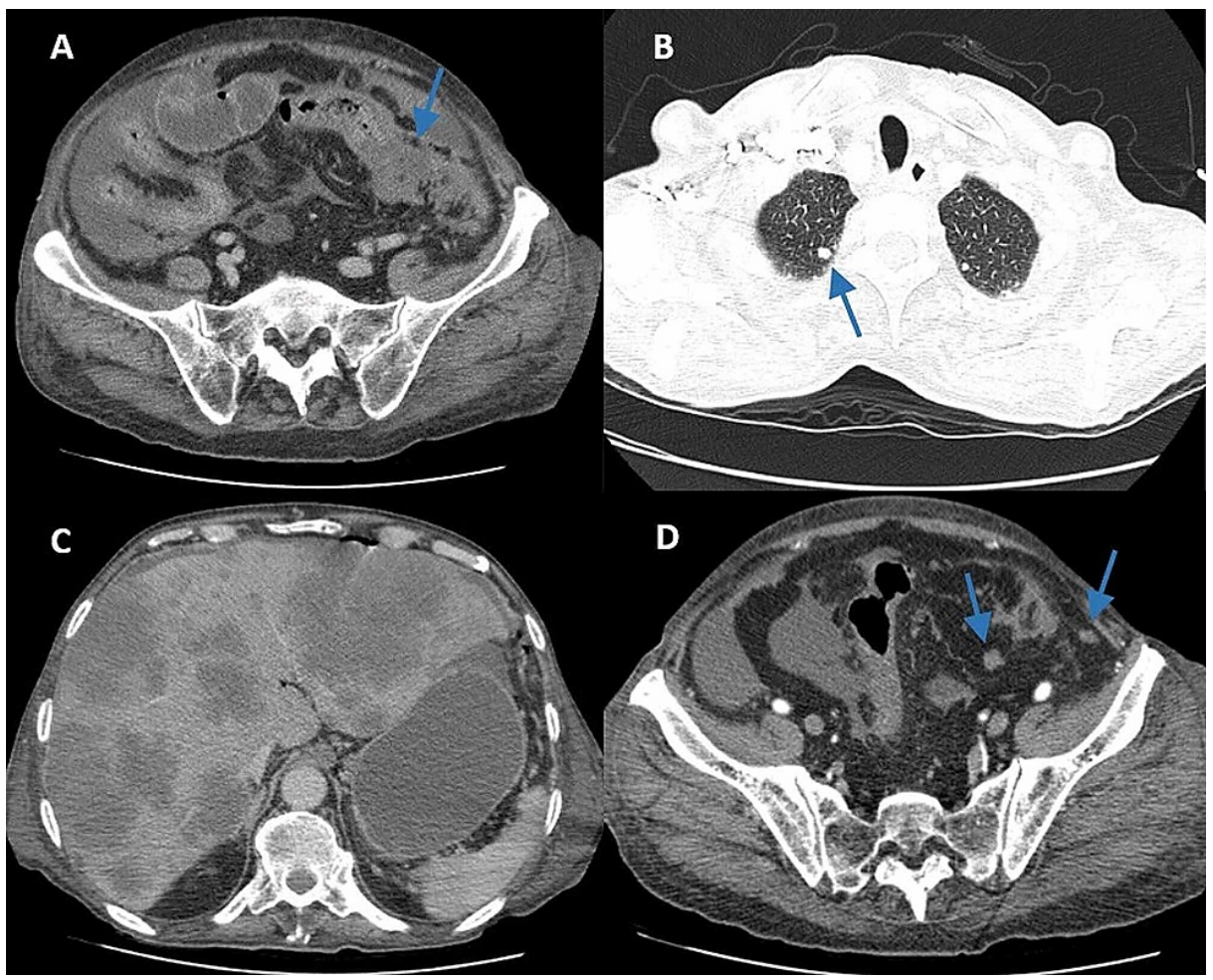

\section{FIGURE 1: CT-scan images}

CT-scan images compatible with sigmoid neoplasia (A); pulmonary metastasis (B); liver metastasis (C); and peritoneal carcinomatosis (D)

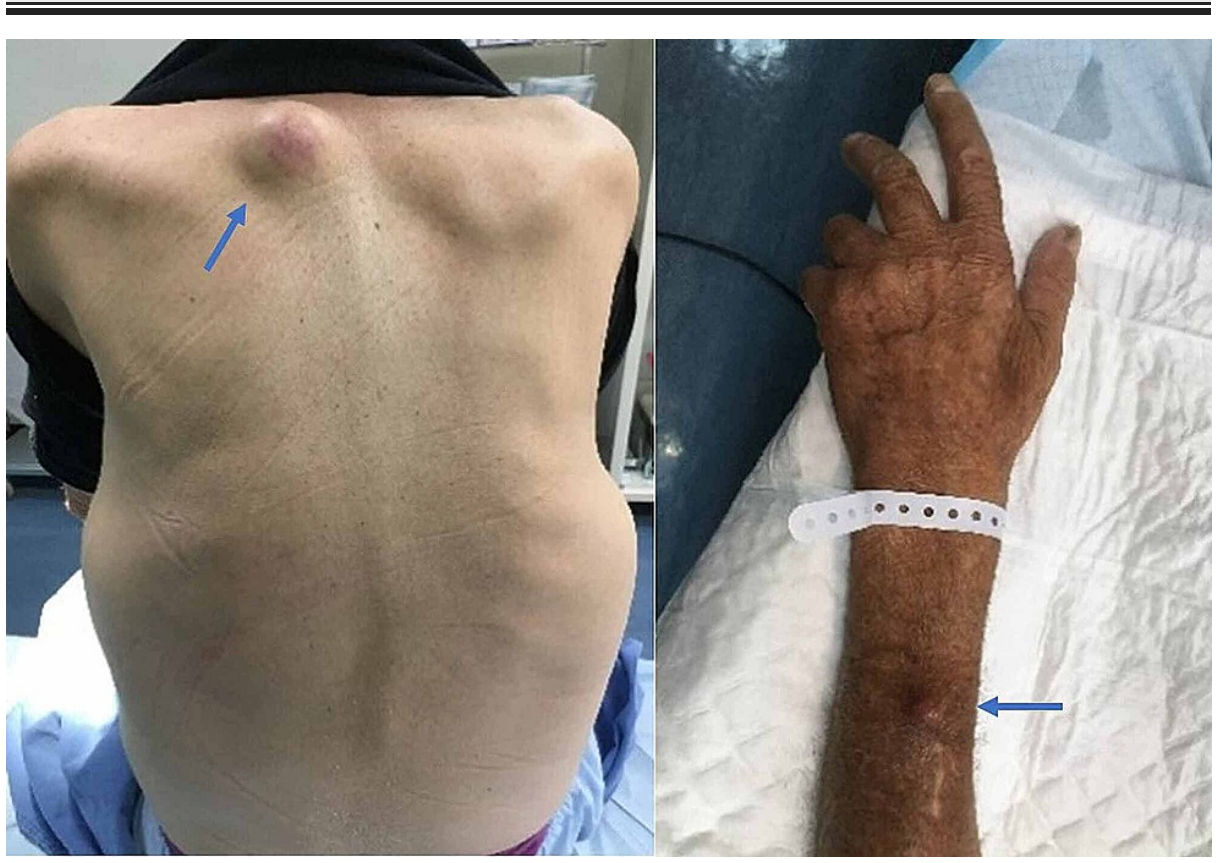

FIGURE 2: Nodular cutaneous lesions at the back and forearm (last one excised for analysis)

The patient died three days after discharge due to a rapid progression of disease and deterioration of his general condition.

Histological results came after patient death: colon biopsy confirmed the presence of colon adenocarcinoma and excisional biopsy of the forearm cutaneous nodule proved to be a dermohypodermic metastasis of an 


\section{Cureus}

adenocarcinoma with colic origin, with positive stain for CK20 and CDX2, and negative stain for CK7, Napsin A, GATA3, mammaglobin, ERG1 and PSA (Figure 3).

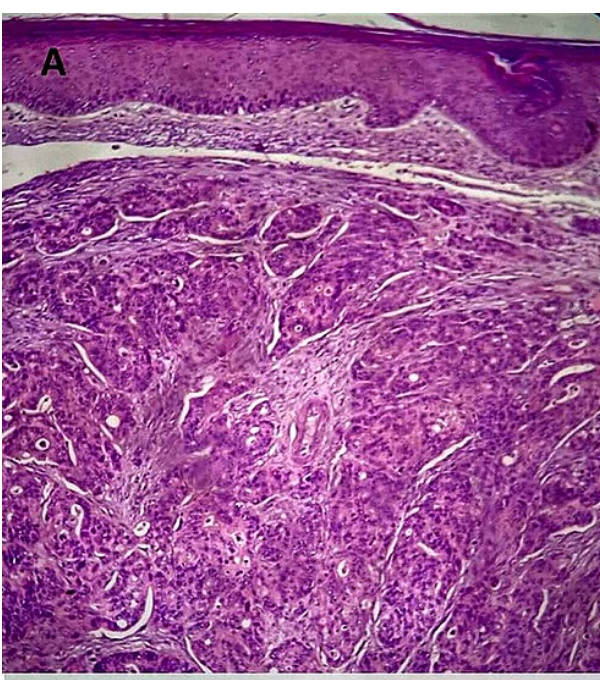

C

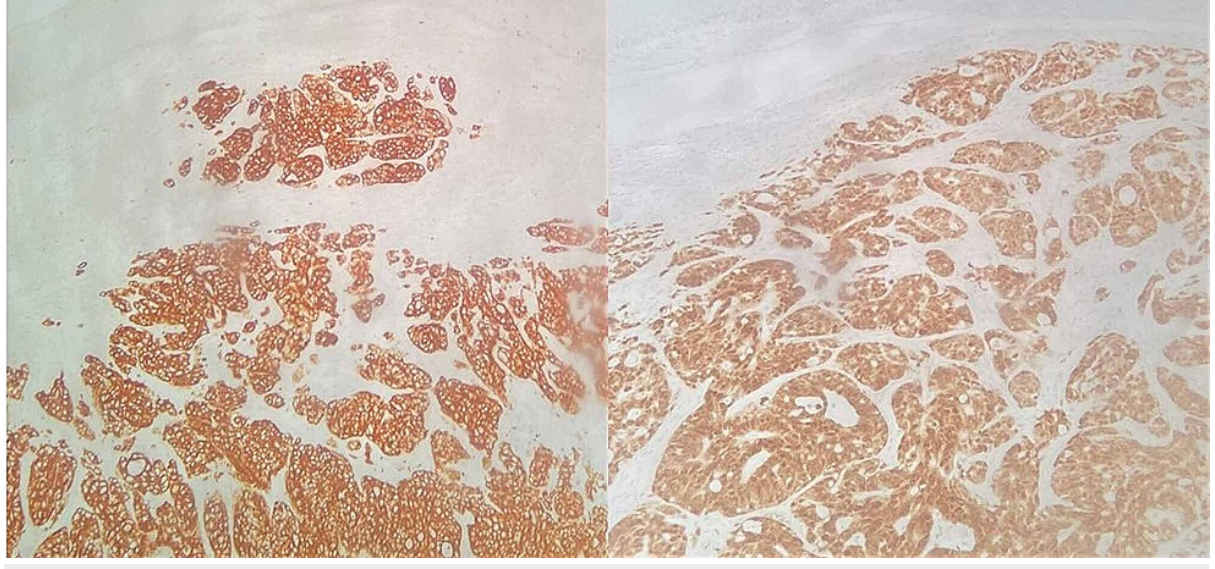

FIGURE 3: Metastatic colon adenocarcinoma involving the skin (A-D)

Haematoxylin-eosin, original magnifications x 40 (A) and x 100 (B); C: cytokeratin 20; D: CDX2 (C-D - original magnifications $\times 40$ ).

Note in B the presence of typical dirty necrotic debris material with karyorrhectic nuclei (black arrow).

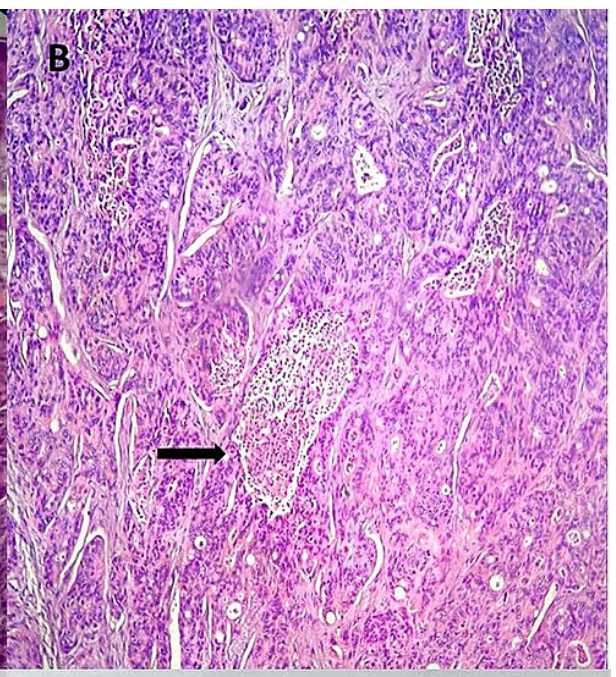

D

(1) 
painless, red/flesh-coloured mobile nodules, single or multiple, but they can mimic other cutaneous processes like lipomas, epidermal cyst, polyps, ulcers, cellulitis, zona zoster [1-2,7-8]. The ultimate diagnosis of cutaneous metastasis from CRC relies on histological evaluation. CK20, CDX2 and CK7 immunostaining are the most helpful markers to distinguish common malignancies, and CRC typically expresses CK20 and CDX2 but not CK7 [7-8,10].

The approach of primary tumour still is the step with the greatest impact on prognosis. Yet, interventions directed to cutaneous metastasis are showing increasingly relevant priorities for managing pain, tumour burden and quality of life, but no standard strategy has been defined [1-2,9-10]. Although conventional techniques like radiation and excision (when surgically feasible) remain the backbone of treatment $[1,4,10]$, immunomodulatory therapies, such as electrochemotherapy and topic chemotherapy, have been showing hopeful results in cutaneous metastasis. However, stronger investigations and systematic studies are still needed $[1,10]$.

\section{Conclusions}

In conclusion, cutaneous metastasis from CRC is a rare phenomenon that usually signifies widespread disease associated with visceral metastasis, a sign of poor prognosis. Nevertheless, a high index of suspicion should be maintained in evaluating cutaneous lesions, particularly in patients with an oncologic past, since cutaneous metastasis could be the initial symptom of disease progression, or even be the first sign that prompts workup for malignancy, allowing for early therapeutic management and improving patient's survival. Patient education also plays a major role in early detection and they should be familiarized with self-examinations, as often they would be the first to notice cutaneous alterations.

\section{Additional Information \\ Disclosures}

Human subjects: Consent was obtained or waived by all participants in this study. Conflicts of interest: In compliance with the ICMJE uniform disclosure form, all authors declare the following: Payment/services info: All authors have declared that no financial support was received from any organization for the submitted work. Financial relationships: All authors have declared that they have no financial relationships at present or within the previous three years with any organizations that might have an interest in the submitted work. Other relationships: All authors have declared that there are no other relationships or activities that could appear to have influenced the submitted work.

\section{References}

1. Choate E, Nobori A, Worswick S: Cutaneous metastasis of internal tumors. Dermatol Clin. 2019 Oct, 37:545554. 10.1016/j.det.2019.05.012

2. Nesseris I, Ditsos I, Tsamakis C, et al.: Cutaneous metastasis of colon adenocarcinoma: a case report and review of the literature. An Bras Dermatol. 2013, 88:56-8. 10.1590/abd1806-4841.20132441

3. Faenza M, Del Torto G, Di Costanzo P, et al.: Large single cutaneous metastasis of colon adenocarcinoma mimicking a squamous cell carcinoma of the skin: A case report. Int J Surg Case Rep. 2019, 56:96-100. 10.1016/j.ijscr.2019.02.043

4. Nashan D, Müller ML, Braun-Falco M, Reichenberger S, Szeimies RM, Bruckner-Tuderman L: Cutaneous mestastases of visceral tumours: a review. J Cancer Res Clin Oncol. 2009, 135:1-14. 10.1007/s00432-0080432-0

5. Ruiz S, Salihi S, Prietto V, et al.: Unusual cutaneous metastatic carcinoma. Ann Diagn Pathol. 2019, 43:151399. 10.1016/j.anndiagpath.2019.08.003

6. Dehal A, Patel S, Kim S, Shapera E, Hussain F: Cutaneous metastasis of rectal cancer: a case report and literature review. Perm J. 2016, 20:74-78. 10.7812/TPP/15-078

7. Saeed S, Keehn C, Morgan M: Cutaneous metastasis: a clinical, pathological, and immunohistochemical appraisal. J Cutan Pathol. 2004, 31:419-30. 10.1111/j.0303-6987.2004.00207.x

8. Bittencourt M, Imbiriba A, Oliveira O, Santos JE: Cutaneous metastasis of colorectal cancer. An Bras Dermatol. 2018, 93:884-88. 10.1590/abd1806-4841.20187610

9. Trujillo-Díaz J, Ruiz-Soriano M, Montes-Manrique M, López-López JC, Vázquez-Fernández A, Rentería JP: Metástasis cutânea de cáncer de colon: una forma de presentación inusual y tardía a tener en cuenta [article in Spanish]. Cir Cir. 2018, 86:285-288. 10.24875/CIRU.M18000041

10. Wong C, Helm M, Kalb R, et al.: The presentation, pathology, and current management strategies of cutaneous metastasis. N Am J Med Sci. 2013, 5:499-504. 10.4103/1947-2714.118918 